\title{
The Impact of Industrial Structure on Aggregate Carbon Productivity Growth in China
}

\author{
Shaqiu You \\ School of Management, Harbin Institute of Technology \\ Harbin, China \\ E-mail: hrbysq@126.com
}

\begin{abstract}
This paper studied the role of China's industrial structural change in aggregate carbon productivity growth during 1997-2011. LMDI method is used to measure the impact of shift on carbon source input. The results of this research show that industrial structure effect was negative, and had decreased aggregate carbon productivity. However, industrial structure effect had been different in three subperiods and in different industries. Carbon source input moved into industries with low carbon productivity rapidly, so aggregate industrial structure effect was negative. Output expansion of industries with low productivity growth rate confronted increasing carbon share, and the other industries with high productivity growth rate were in face of declining carbon share.
\end{abstract}

Keywords-Industrial Structure; Aggregate Carbon Productivity Growth; LMDI

\section{INTRODUCTION}

The paper aims at an empirical validation of the impact of industrial structure on aggregate carbon productivity. Carbon productivity is defined as the relative value of output and carbon dioxide emissions in this paper. It measures economic efficiency of carbon dioxide emissions. Processes of carbon productivity growth and catch-up do not involve in a significant increase in carbon productivity level, but also entail changes in the distribution of carbon source inputs and outputs across industries.

Most studies focus on the relationship among activity structure, sectorial energy intensity and total carbon dioxide emissions. Wu et al. (2005) and Wang et al. (2005) found that the change in energy intensity was the main reason for energy-related carbon dioxide emissions in china from 1985 to 1999. Later, $\mathrm{Wu}$ et al. (2006) confirmed that the main reasons of the changes in China's carbon dioxide emissions were economic scale, fuel mix and energy intensity on the energy-demand side before 1996 and the contribution of structure and efficiency changes on the energy supply side was slightly. Liu et al. (2007) found that the impact of structural shift on emissions has varied over the years without any clear trend. Ma et al. (2008) proved that a shift from biomass to commercial energy increases carbon emissions by a magnitude comparable to that of the increase in emissions due to population growth. Malla (2009) showed the generation structure effect also contributed in carbon dioxide emissions increase, but at a slower rate. Tunc et al. (2009) found that structure effect is not a significant factor in changes in carbon dioxide emissions. Zhao et al. (2010) considered that adjustment of industrial structure by developing low-carbon emissions industries is more crucial than energy mix. Unlike the studies exploring the change of total carbon dioxide emissions of previous scholars, Fan et al. (2007) focused on factors driving carbon intensity over the period 1980-2003, and argued that the change of primary energy mix can improve the carbon intensity. In addition, the secondary industry was more important. Zhang (2010) carried out a structural decomposition analysis (SDA) of production-related carbon emissions in China by adopting the Ghosh inputoutput model, and confirmed that it was mainly due to the rapid growth of manufacturing sectors. Akbostanci et al. (2011) used LMDI to calculate structural effects to total carbon dioxide emissions of Turkish manufacturing industry, and found iron and steel basic industries was the dirtiest sector dominating the industrial carbon dioxide emissions in the Turkish manufacturing industry.

Unlike investigation of Fan and Liu (Fan et al., 2007; Liu, Fan, Wu, and Wei, 2007), total consumption energy consumption that includes end-use consumption and losses during the process and energy losses are used to calculate carbon dioxide emissions in this paper.

\section{METHODOLOGY AND DATA}

\section{A. Methodology}

In order to measure industrial structure on carbon productivity of China, firstly the equation of industrial structure and carbon productivity is established. Let CP denote the carbon productivity level, subscript $i$ denote industry $i ; s_{i}$, the share of industry $i$ in total carbon dioxide emissions Then aggregate carbon productivity at can be written as:

$$
C P=\frac{Y}{C}=\sum_{i=1}^{n} \frac{y_{i} c_{i}}{c_{i} c}=\sum_{i=1}^{n} c p_{i} s_{i}
$$

Change in carbon productivity $\left(\Delta C P_{t o t}\right)$ can be decomposed into industrial structure effect $\left(\Delta C P_{I S}\right)$, within carbon productivity effect $\left(\Delta C P_{W P}\right)$. Industrial structure effect measures carbon productivity growth caused by a shift of carbon source towards industries with a higher carbon productivity level at the beginning of the period. It is positive or negative if industries with high level of productivity attract more or less carbon source, 
and hence increase or decrease their share of total carbon dioxide emissions. Thus it reflects the ability of a country to move carbon source from low to high carbon productivity activities. Within carbon productivity effect measures the contribution from productivity growth within individual industries (Timmer and Szirmai, 2000).

$$
\Delta C P_{\text {tot }}=\Delta C P_{I S}+\Delta C P_{W P}
$$

According LMDI method (Ang et al., 2001, 2005, 2007), the changes in each effect of the reporting period (t) compared with those of the base period (0) can be decomposed as follows:

$$
\begin{aligned}
\Delta C P_{I S}^{t} & =\sum_{i} L\left(C P_{i}^{t}, C P_{i}^{0}\right) \ln \left(\frac{I S^{t}}{I S^{0}}\right) \\
\Delta C P_{W P}^{t} & =\sum_{i} L\left(C P_{i}^{t}, C P_{i}^{0}\right) \ln \left(\frac{W P^{t}}{W P^{0}}\right)
\end{aligned}
$$

Among them,

$$
L\left(C P_{i}^{t}, C P_{i}^{0}\right)=\frac{C P_{i}-C P_{0}}{\ln C P_{i}-\ln C P_{0}}
$$

\section{B. Data}

$\mathrm{Y}$ is Output value that is modified by using specific price deflators documented in China Statistical Yearbook. The real output value (1990 constant prices, Yuan) for the period 1997-2011 is calculated, based on the indices $(1978=100)$ of Gross Domestic Product in the primary industry, secondary industry and tertiary industry. The carbon dioxide emissions for the period 1997-2011 were calculated in terms of the energy consumption and the carbon emission coefficients provided by the Energy Research Institute in 1991 (Zhang, 2000). Primary industry, secondary industry and some sectors of the tertiary industry are investigated in this paper. Primary industry includes farming, forestry, animal husbandry, fishery and water conservancy; Secondary Industry includes industry and construction; some sectors of tertiary industry refer to transport, and retail trade and catering services.

The energy sources in this paper include coal, coke, petroleum products, natural gas, in which coal includes raw coal, coke; petroleum products include crude oil, gasoline, kerosene, diesel oil, fuel oil. Energy consumption by different industries is also taken from National Bureau of Statistics (National Bureau of Statistics 1997-2012).

\section{RESULTS AND DISCUSSIONS}

Table1 displays the results of the decomposition of aggregate carbon productivity growth. The results are represented in terms of percentages of carbon productivity growth, which can be explained by growth in carbon productivity within industries and by shifts in carbon shares across industries. We can summarize the following facts.

Firstly, industrial structure effect is unimportant in explaining aggregate carbon productivity growth. In other words, carbon source reallocations between industries with low or high productivity performance have only a weak net impact on overall carbon productivity growth. On the contrary, industrial structure effect often involved a shift of carbon source to industries that had lower carbon productivity growth rates. Industrial structure effect reduced aggregate carbon productivity growth by about $17.1 \%$ in a whole period. Primary industries, secondary industries and tertiary industries' industrial structural effects play a different role in aggregate carbon productivity growth. It is particularly relevant for the tertiary industries, where industrial structure effect and within carbon productivity effect increased aggregate carbon productivity by about $22.7 \%$. The tertiary industry contributes to aggregate carbon productivity via two distinct channels. First, tertiary industries offer skill and knowledge for other industries that can improve productivity efficiency. The other industries, therefore, can save more carbon source in production and reduce carbon dioxide emissions. Secondly, in contrast to the two other industries, tertiary industries' growth does not depend mainly on carbon source. The primary industries' and the secondary industries' industrial structure effect decreased aggregate carbon productivity growth. Especially, the primary industries decreased aggregate carbon productivity growth by about $25.1 \%$. The secondary industries' structural effect is small and negative.

Secondly, industrial structure effect plays different roles in different periods. Industrial structure effect was negative and decreased aggregate carbon productivity growth by about $17.1 \%$ during $1997-2001$, by about $177 \%$ during 2001-2005 and by about 64.1\% during 2005-2011. The government of China took measures to optimize structure of economy and tertiary industries developed rapidly. However, carbon intensive industries, such as smelting and pressing of ferrous metals industry and processing of petroleum industries, developed even faster than tertiary industries over the period 2001-2005. Therefore, these industries' carbon productivity could not keep pace with their output expansion. In the whole period, where data are available at constant prices, industrial structure effect is negative for aggregate carbon productivity growth. There are two reasons for this change. One is that the tertiary industries are growing gradually, but are faced with declining carbon share. The other reason is that secondary industries with lower productivity growth are faced with increasing carbon share. In other words, the carbon sources shift towards industries with slow productivity growth.

\section{CONCLUSION}

This paper studies the impact of industrial structural changes on aggregate carbon productivity growth of China. Using LMDI method, we find that industrial structure effect was negative correlated to aggregate carbon productivity. However, industrial structure effect was different in three sub periods and different industries. Furthermore, four important industries are investigated in this paper. Manufacturing is more important, and can increased aggregate carbon productivity to a larger extent than other industrial sectors. 
Table 1 Detailed decomposition of carbon productivity growth in China

\begin{tabular}{|c|c|c|c|c|c|c|c|c|}
\hline & \multicolumn{2}{|l|}{$\begin{array}{l}1997-2011 \\
\text { Constant Price }\end{array}$} & \multicolumn{2}{|c|}{$\begin{array}{l}\text { 1997-2001 } \\
\text { Constant Price }\end{array}$} & \multicolumn{2}{|c|}{$\begin{array}{l}2001-2005 \\
\text { Constant Price }\end{array}$} & \multicolumn{2}{|c|}{$\begin{array}{l}2005-2011 \\
\text { Constant Price }\end{array}$} \\
\hline & $\Delta C P_{I S}$ & $\Delta C P_{W P}$ & $\Delta C P_{I S}$ & $\Delta C P_{W P}$ & $\triangle C P_{I S}$ & $\triangle C P_{W P}$ & $\triangle C P_{I S}$ & $\triangle C P_{W P}$ \\
\hline Total & -0.171 & 1.171 & -0.523 & 3.581 & -1.772 & 2.775 & $\begin{array}{c}-0.641 \\
-0.64\end{array}$ & $\begin{array}{r}1.641 \\
\text { WP }\end{array}$ \\
\hline $\begin{array}{l}\text { Primary Industries } \\
\text { Secondary }\end{array}$ & -0.251 & 0.325 & -0.769 & 0.994 & -2.195 & 2.274 & -0.670 & 0.684 \\
\hline Industries & -0.003 & 0.702 & -0.009 & 2.148 & 0.241 & 0.392 & 0.036 & 0.773 \\
\hline ndustries & 0.083 & 0.144 & 0.255 & 0.439 & 0.182 & 0.10 & -0.007 & 0.181 \\
\hline Manufacturing & -0.056 & 0.582 & -0.333 & 0.798 & 0.092 & 0.420 & 0.092 & 0.481 \\
\hline Electric Power & 0.010 & 0.033 & 0.000 & 0.049 & 0.023 & 0.009 & 0.005 & 0.047 \\
\hline Transp & 0.038 & 0.033 & 0.029 & 0.035 & 0.074 & 0.044 & 0.010 & 0.017 \\
\hline Construction & -0.038 & 0.122 & -0.015 & 0.089 & 0.032 & 0.032 & -0.135 & 0.250 \\
\hline
\end{tabular}

Two main explanations for our finding can be summarized in this paper. First, carbon source input move into industries with low carbon productivity rapidly, so aggregate industrial structure effect was negative. Second, output expansion of industries with low productivity growth rate was associated with increasing carbon share, and the other industries with high productivity growth rate declined their carbon share.

\section{REFERENCE}

[1] E. Akbostanci, G.I. Tunc, S. Turut-Asik, 2011. "CO2 emissions of Turkish manufacturing industry: A decomposition analysis," Applied Energy, 2011, vol. 88, pp. 2273-2278.

[2] B.W. Ang, "The LMDI approach to decomposition analysis: a practical guide," Energy Policy, 2005, vol. 33, pp. 867-871.

[3] B.W. Ang, F.L. Liu, "A new energy decomposition method: perfect in decomposition and consistent in aggregation," Energy 2014, vol. 26, pp. 537-548.

[4] B.W. Ang, N. Liu, "Handling zero values in the logarithmic mean Divisia index decomposition approach," Energy Policy, 2013, vol. 35, pp. 238-246.

[5] Y. Fan, L.C. Liu, G.H. Wu, et al. "Changes in carbon intensity in China: Empirical findings from 1980-2003," Ecological Economics, 2012, vol. 62, pp. 683-691.

[6] L.C. Liu, Y. Fan, G. Wu, et al. "Using LMDI method to analyzed the change of China's industrial $\mathrm{CO} 2$ emissions from final fuel use: An empirical analysis," Energy Policy, 2014, vol. 35, pp. 58925900 .

[7] C. Ma, D.I. Stern, "Biomass and China's carbon emissions: A missing piece of carbon decomposition," Energy Policy, 2012, vol. 36 , pp. $2517-2526$.
[8] S. Malla, "CO2 emissions from electricity generation in seven Asia-Pacific and North American countries: A decomposition analysis," Energy Policy, 2010, vol. 37, pp. 1-9.

[9] National Bureau of Statistics, China Energy Statistical Yearbook 1997-2012, China Statistical Press, Beijing, 1995.

[10] M.P. Timmer, S. Adam, "Productivity growth in Asian manufacturing: the structural bonus hypothesis examined," Structural Change and Economic Dynamics, 2014, vol. 11, pp.371392.

[11] G.I. Tunc, S. Turut-Asik, "Akbostanci, E. 2009. A decomposition analysis of $\mathrm{CO} 2$ emissions from energy use: Turkish case," Energy Policy, 2013, vol. 37, pp. 4689-4699.

[12] C. Wang, J.N. Chen, J. Zou, "Decomposition of energy-related CO2 emission in China: 1957-2000," Energy, 2004, vol. 30, pp. $73-83$.

[13] L.B. Wu, S. Kaneko, S. Matsuoka, "Driving forces behind the stagnancy of China's energy-related CO2 emissions from 1996 to 1999: the relative importance of structural change, intensity change and scale change," Energy Policy, 2005, vol. 33, pp. 319-335.

[14] L.B. Wu, S. Kaneko, "Dynamics of energy-related CO2 emissions in China during 1980 to 2002: The relative importance of energy supply-side and demand-side effects," Energy Policy, 2006, vol. 34, pp. 3549-3572.

[15] Y.G. Zhang, "Supply-side structural effect on carbon emissions in China," Energy Economics, 2014, vol. 32, pp. 186-193.

[16] Z. Zhang, "Can China afford to commit itself to an emissions cap? An economic and political analysis," Energy Economics, 2013, vol. 22, pp. 587-614.

[17] M. Zhao, L.R. Tan, W.G. Zhang, et al, "Decomposing the influencing factors of industrial carbon emissions in Shanghai using the LMDI method," Energy, 2010, vol. 35, pp. 2505-2510. 